\title{
GESTÃO SOCIAL E AMBIENTAL EM PEQUENAS E MÉDIAS EMPRESAS: INFLUENCIA E PODER DOS STAKEHOLDERS
}

\author{
José Edson Moysés Filho \\ zezemoyses@laffriolee.com.br \\ Universidade Nove de Julho - SP / Brasil \\ Andrea Leite Rodrigues \\ andrea.leite@fgv.br \\ Universidade de São Paulo - SP / Brasil \\ Sérgio Luiz do Amaral Moretti \\ moretti@uninove.br \\ Universidade Nove de Julho - SP / Brasil
}

Recebido em 13/04/2010

Aprovado em 16/09/2010

Disponibilizado em 01/04/2011

Avaliado pelo sistema double blind review

Revista Eletrônica de Administração

Editor: Luís Felipe Nascimento

ISSN 1413-2311 (versão on-line)

Editada pela Escola de Administração da Universidade Federal do Rio Grande do Sul.

Periodicidade: Quadrimestral

Sistema requerido: Adobe Acrobat Reader.

\section{INTRODUÇÃO}

Nas décadas de 1990 e 2000, a produção intelectual sobre as ações sociais das empresas cresceu tanto nacional quanto internacionalmente. No entanto, observa-se um número restrito de trabalhos sobre RSE em PME e menos ainda sobre a influência dos stakeholders nessa relação. A ampliação dos estudos nesta área torna-se importante à medida que crescem em quantidade e em importância os empreendimentos de pequeno e médio porte. Em um artigo no início da década de 1990, Thompson e Smith (1991) já chamavam atenção para a importância e falta de pesquisas sobre o assunto. Estudos como os de Fuller e Tian (2006), Jenkins (2006), Longo, Mura e Bonoli (2005), Roberts, Lawson e Nicholls (2006), Spence (2007), Uhlaner, Goor-Balk e Masurel (2004), Williamson, Lynch-Wood e Ramsay 
(2006), e mais recentemente Avram e Kühne (2008), Fassin (2008), Jenkins (2009), Mankelow (2008) e Murilo E Lozano (2009) trataram dos desafios e dilemas desta relação.

Adicionalmente, tem-se uma ampla produção intelectual que propõe analisar as organizações como parte importante da rede de relações que influenciam suas atividades e, consequentemente, geram impactos em seus modelos de gestão. Analogamente, há poucos trabalhos sobre as PME abordando a gestão de ações sociais e ambientais. Poucos abordaram tal aspecto, como Jenkins (2006), Perrini (2006) e Spence, Coles e Harris (2001). Sua principal contribuição foi trazer ao debate a interdependência das ações de mercado, por meio das interações dos seus diversos agentes. Como um móbile, os movimentos se tornam resultado de interações da parte e todo e vice-versa (MORETTI, 2005).

A gestão social e ambiental deve considerar as relações entre os seus stakeholders, ou seja, compatibilizar as necessidades e particularidades de vários públicos, cada um com interesses próprios e nem sempre harmonizáveis. Gerenciar esses interesses conflitantes poderia, portanto, ser considerada a primeira e mais difícil tarefa de um gestor organizacional (HARRISON; FREEMAN, 1999). Esta forma de pensar a gestão - como conflitos entre interesses - impulsionou a aceitação da abordagem dos stakeholders na análise dos dilemas éticos em gestão, uma vez que trata dos impactos da atividade empresarial sobre a totalidade dos públicos envolvidos em suas atividades e não apenas acionistas e proprietários (MOYSÉS FILHO e RODRIGUES, 2009).

Para efeitos desse trabalho se adotará a definição de RSE proposta pelo Instituto Ethos de Empresas e Responsabilidade Social (Instituto Ethos), já que o campo empírico ocorrerá entre empresas que adotaram o Programa Tear, cujas bases são fundamentadas na referida definição e expressas no documento chamado Linha de Base, desenvolvido pelo Instituto Ethos para garantir a consolidação do Programa Tear.

Responsabilidade social empresarial é a forma de gestão que se define pela
relação ética e transparente da empresa com todos os públicos com os quais
ela se relaciona, pelo estabelecimento de metas empresariais que
impulsionem o desenvolvimento sustentável da sociedade, preservando
recursos ambientais e, culturais para as gerações futuras, respeitando a
diversidade e promovendo a redução das desigualdades sociais
(INSTITUTO ETHOS DE EMPRESAS E RESPONSABILIDADE
SOCIAL, 2007).

Não se pode deixar de destacar a função exercida pelas metas empresariais na adoção da gestão social e ambiental responsável que junta, em um mesmo processo, as questões sociais, ambientais e comerciais. Ao que tudo indica o Instituto está alinhado com o slogan REAd - Edição 68, Volume 17, No 1, jan/abr 2011 - p. 204-236 
que se popularizou após o Pacto Global de 2000, sob os auspícios da Organização das Nações Unidas (ONU), como tripple botton line. Trata-se de uma proposta para conciliar os campos sociais, ambientais e econômicos, com o objetivo de assegurar uma sociedade e ambientes mais equilibrados (GOMES; MORETTI, 2007).

Não obstante, a quantidade de trabalhos que abordam a gestão voltada para stakeholders no âmbito das PME é, contudo, reduzida. Menores ainda aquelas que tratam dos desafios e dilemas da RSE em PME, considerando a influência de stakeholders externos. Visando contribuir para preencher essa lacuna, este trabalho tem o objetivo de entender essa relação no âmbito de PME a partir da influência de públicos relevantes externos representados por grandes empresas-âncoras. O objetivo deste trabalho, portanto, foi analisar como grandes empresas influenciam seus fornecedores, normalmente PME, em prol da adoção de práticas de gestão sociais e ambientais. Para isso foi utilizada a metodologia de pesquisa exploratória de caráter qualitativo e, como técnica de pesquisa, um estudo de casos múltiplos. O campo foi conduzido para 3 conjuntos de 3 empresas cada um, contando com a formação: 1 empresaâncora, membro do Instituto Ethos, e 2 fornecedores considerados PME, totalizando nove empresas estudadas.

As empresas que compuseram os três estudos de caso foram escolhidas a partir do Programa Tear - Tecendo Redes Sustentáveis, desenvolvido pelo Instituto Ethos, organização de referência no Brasil em RSE que se legitima na sociedade brasileira por meio de seus propósitos na promoção da cidadania corporativa, com o apoio do Banco Interamericano de Desenvolvimento (BID). O Programa nasceu em 2005, com o objetivo de atingir PME com o auxílio de empresas-âncoras, que possuíssem ascensão sobre elas em suas cadeias de suprimentos. A lógica do Programa Tear residiu em fazer com que as grandes empresas - ou âncoras - influenciassem fornecedores com perfil de PME estimulando-os a aderir a práticas de gestão referenciadas pelos Indicadores Ethos. O primeiro Programa Tear terminou em 2008 e envolveu 9 empresas âncoras e 108 PME em todo Brasil.

O trabalho está estruturado de forma a apresentar uma revisão da literatura sobre o tema, a metodologia do estudo de caso múltiplo, os resultados e discussão e as considerações finais.

REAd - Edição 68, Volume 17, No 1, jan/abr 2011 - p. 204-236 


\section{FUNDAMENTAÇÃO TEÓRICA}

A RSE como campo de estudo apresenta não só uma paisagem de teorias, mas, também uma proliferação de abordagens as quais são muitas vezes controversas. Moretti e Campanário (2009) fizeram um levantamento bibliométrico da produção da RSE nos anais do Encontro da Associação Nacional de Pós-Graduação e Pesquisa em Administração (Enanpad), para o período de 1997-2008, suas conclusões foram que o tema é polissêmico e "o campo da RSE está longe de contar com um referencial teórico consistente, sugerindo a necessidade de uma agenda de pesquisas mais ambiciosa" (p. 24).

Para a melhor compreensão das forças envolvidas nesta discussão selecionaram-se duas linhas principais que concentram as questões mais importantes; a assimetria de suas proposições poderá fornecer uma ideia da intensidade do debate. As classificações encontradas são variadas, de forma que para as necessidades desse estudo desenvolveu-se uma taxonomia baseada em Moretti (2005) que pareceu mais adequada a esse propósito.

A primeira linha (FRIEDMAN, 1970; JENSEN, 2002) postula que as empresas não devem se preocupar com a responsabilidade social e sim com seus afazeres, ou seja, devem se concentrar nos negócios; com isso, todos saem beneficiados a longo prazo, ela é muitas vezes denominada abordagem contratual. O principal ponto de tensão - como denominam autores dessa linha - é com o impacto sobre a lucratividade que ações fora da alçada da empresa podem acarretar.

A segunda linha prega que as empresas devem se envolver com a responsabilidade social, por razões diversas. Dividiu-se esta linha em três variantes: a estratégica (CARROL, 1999; MARGOLIS; WALSH, 2003; VENTURA, 2003; WOOD, 1991) vê oportunidades de negócios no processo; a ética dos negócios (CURADO, 2003; FERREL; FRAEDRICH; FERREL, 2001; KREITLON, 2004; LIPOVETSKY, 2004) percebe as empresas como agentes morais e portadoras de uma ética empresarial; a sistêmica (DONALDSON; PRESTON, 1995; FREEMAN, 2000, 2003; LOGSDON; YUTHAS, 1997) postula o envolvimento das empresas com os diversos públicos de interesse, conhecida também como abordagem dos stakeholders.

Como se pode perceber são duas visões opostas do sistema econômico e social. A primeira é fortemente apoiada no aspecto legal, que garante os direitos dos acionistas em retirar o lucro das operações de suas empresas após o recolhimento dos impostos, taxas e, direitos patrimoniais e legais. A segunda se fundamenta em uma visão integrada e idealizada

REAd - Edição 68, Volume 17, No 1, jan/abr 2011 - p. 204-236 
da sociedade e do sistema econômico, e tem como sustentáculo uma visão mais abrangente das poderosas interações desses dois macrossistemas.

Para fugir desta dicotomia, Ventura (2003) dedicou-se a analisar a proposta de Boltanski e Chiapello (2002) sobre o novo espírito do capitalismo. De acordo com a autora a adaptação capitalista se dá a partir da necessidade das empresas justificarem sua atuação social como uma prova de boa vontade, de fato, um ajuste do sistema aos novos tempos de pressão social. Kreitlon (2004) demonstrou que a abordagem monológica, e predominante da RSE, evita qualquer questionamento mais profundo e que o argumento de uma empresa ética parece bastar por si mesmo para justificar o movimento. A filantropia ainda impera, e o que se percebe é a preocupação com resguardar a imagem de compromisso com a sociedade maior do que a ação social em si. Todos esses autores poderiam estar mais presentes no corpus dos trabalhos posteriores, mas não foi isso o que se viu. Algumas exceções vêm a seguir.

Passador, Canopf e Passador (2005) em pesquisa de publicações sobre RSE nos anais do Enanpad revelam que os autores pesquisados têm um ponto em comum, de que a exigência da sociedade é um fator suficiente e justificador. Macke e Carrion (2006) propõem que seja incluído no debate o conceito de capital social, impondo uma perspectiva interdisciplinar no campo de estudos da RSE, questão justificada pela complexidade dos vetores envolvidos em sua elaboração. A vertente econômica obscurecida pelo tratamento operacional sob a qual a RSE tem sido analisada não considera a importância de todos os outros aspectos sociais, pessoais e ambientais, por exemplo, negligenciados. A conclusão de Pereira e Campos (2006) vai de encontro às considerações feitas na introdução deste estudo e sustentam que "as definições acerca da responsabilidade social não demonstram pleno consenso teórico em função do contexto sócio-cultural e econômico em que cada uma delas foi concebida" (PEREIRA; CAMPOS, 2006, p. 13).

Como se vê, as teorias e abordagens mais relevantes da RSE tendem a focar aspectos econômicos, políticos, éticos e de integração social (GARRIGA; MELÉ, 2004). Alguns estudos apontam que a RSE parece estar atrelada a certas utilizações, tal como servir como mecanismo de autocontrole institucional como prega Wood (2008), para quem as instituições não existem para servir os seus próprios fins, mas sim para servir as necessidades das sociedades e de seus povos. Empresas, como todas as outras instituições da sociedade, têm suas funções vitais, mas nunca são completamente livres para agir como entidades independentes.

REAd - Edição 68, Volume 17, No 1, jan/abr 2011 - p. 204-236 
Para Puncheva (2008), ações institucionais incluem tudo o que uma empresa faz para verificar se gestão, comportamento e resultados estão em conformidade com as normas da sociedade em que atua. Os diversos stakeholders ao interagirem com a empresa estabelecem um relacionamento, no qual a gestão das suas ações socialmente responsáveis pode ser fundamentada em regras de intercâmbio. A gestão e relacionamento de uma empresa com seus públicos, de acordo com a autora estão relacionados com a legitimidade social, com a legitimidade pragmática, com troca de benefícios entre as partes envolvidas e com a reputação organizacional. Da perspectiva da cidadania organizacional, o termo reputação corporativa demonstra a capacidade de a empresa entregar valor para todos os envolvidos em seu negócio e refletir o desempenho da organização em múltiplas áreas, tanto em desempenho financeiro, governança e gestão, quanto em responsabilidade social.

A gestão das ações socialmente responsáveis "está diretamente ligada às interações da empresa e seus stakeholders, assim como a forma de comunicação entre as partes, resultando no desempenho da reputação corporativa” (MOYSÉS FILHO, 2009, p.41). A importância das ações e resultados organizacionais para os envolvidos determina a sua vontade de desenvolver ações em relação à empresa (MITCHELL; AGLE; WOOD, 1997). Adicionalmente torna-se essencial, a todos esses públicos, a oportunidade de interagir com a gestão da empresa, desenvolvendo mecanismos para influenciar sua reputação.

Segundo King (2008), a empresa tem que gerir adequadamente as suas relações com os vários intervenientes para desenvolver um aceitável desempenho corporativo social. Para o autor, os administradores da organização teriam uma tendência a responder somente aos stakeholders que possuam três principais atributos: poder, legitimidade e urgência. A ausência de qualquer um deles demonstra pouca influência sobre o funcionamento interno de uma corporação.

A partir de tais atributos, Mackenzie (2007) postula que as estratégias de grandes empresas deveriam conter construtivamente políticas para abordar problemas de incentivos às pequenas empresas por meio de revisão de riscos gerados pelo desempenho do sistema de gestão naquelas áreas de negócios em que o mercado é falho, e desenvolvendo modificações em seus objetivos e desempenho de metas. Para o autor, as empresas veem a não conformidade em RSE como fonte de risco para sua reputação com suas partes interessadas. Nesta esfera de discussão a abordagem dos stakeholders oferece uma fundamentação relevante acerca das responsabilidades de uma empresa. 


\section{MODELO CONCEITUAL}

A pesquisa de campo foi delineada a partir de um modelo conceitual que serviu de orientação para a exploração das relações entre PME e empresas-âncora, e que oferecesse interpretações alternativas para as evidências que certamente surgiriam no decorrer de nossa pesquisa (MILES; HUBERMAN, 1994; FLICK, 2004). As PME têm enfrentado, por diversos meios, pressão crescente para tornarem-se socialmente responsáveis. As partes interessadas, consumidores, fornecedores, funcionários, sindicatos e ONGs pressionam-nas a incorporar em seu modelo de gestão as ações socialmente responsáveis (SCHERER; PALAZZO; BAUMANN, 2006). Estes grupos, ao se relacionarem influenciam em maior ou menor grau suas formas de gestão (CLARKSON, 1994; FASSIN, 2008), articulando um sentimento de geração de valor que impulsiona a empresa para perseguir desempenho superior, não só em propósito organizacional, como também no mercado (FREEMAN; WICKS; PARMAR, 2004).

A participação nos programas aplicados em rede parece favorecer a mobilização para a RSE (TILLEY, 2000). Partindo dessa premissa, utilizou-se para a pesquisa o Programa Tear, iniciativa conjunta do Instituto Ethos e do BID, cujo objetivo era mobilizar grandes empresas (ou âncoras) no sentido de viabilizar fornecedores PME a conhecer e adotar práticas de gestão social e ambientalmente responsáveis. As PME por possuírem características peculiares (CERA; ESCRIVÃO FILHO, 2003), ao adotar tais mudanças têm sua gestão impactada e devem manter desempenho econômico positivo, além de gerar valores intangíveis para as partes interessadas.

O Programa Tear prometia um desempenho econômico positivo quando atrelado na melhoria das relações comerciais com seu parceiro envolvido, redução de custos, aumento de receita, identificação de oportunidades de desenvolvimento de novos produtos e serviços, acesso a novos mercados, ganhos de competitividade e produtividade para as empresas da cadeia de valor. E, também, um desempenho de valores intangíveis por meio de maior incorporação da sustentabilidade em sua gestão, modelo e referência da multiplicação das melhores práticas no seu segmento de atuação, reputação, visibilidade e ou projeção nacional e internacional e contribuição para a sustentabilidade para a sociedade.

A abordagem para explorar o comportamento empresarial, por meio da implantação de ações socialmente responsáveis no ambiente em que estão inseridas, e as maneiras desenvolvidas para lidar com outras organizações têm fundamento no pressuposto de que as

REAd - Edição 68, Volume 17, No 1, jan/abr 2011 - p. 204-236 
pequenas corporações preferem aprender por meio de redes e de seus pares, tornando possível seu maior envolvimento com a RSE (JENKINS, 2006). O funcionamento deste mecanismo está resumido graficamente na Figura 1.

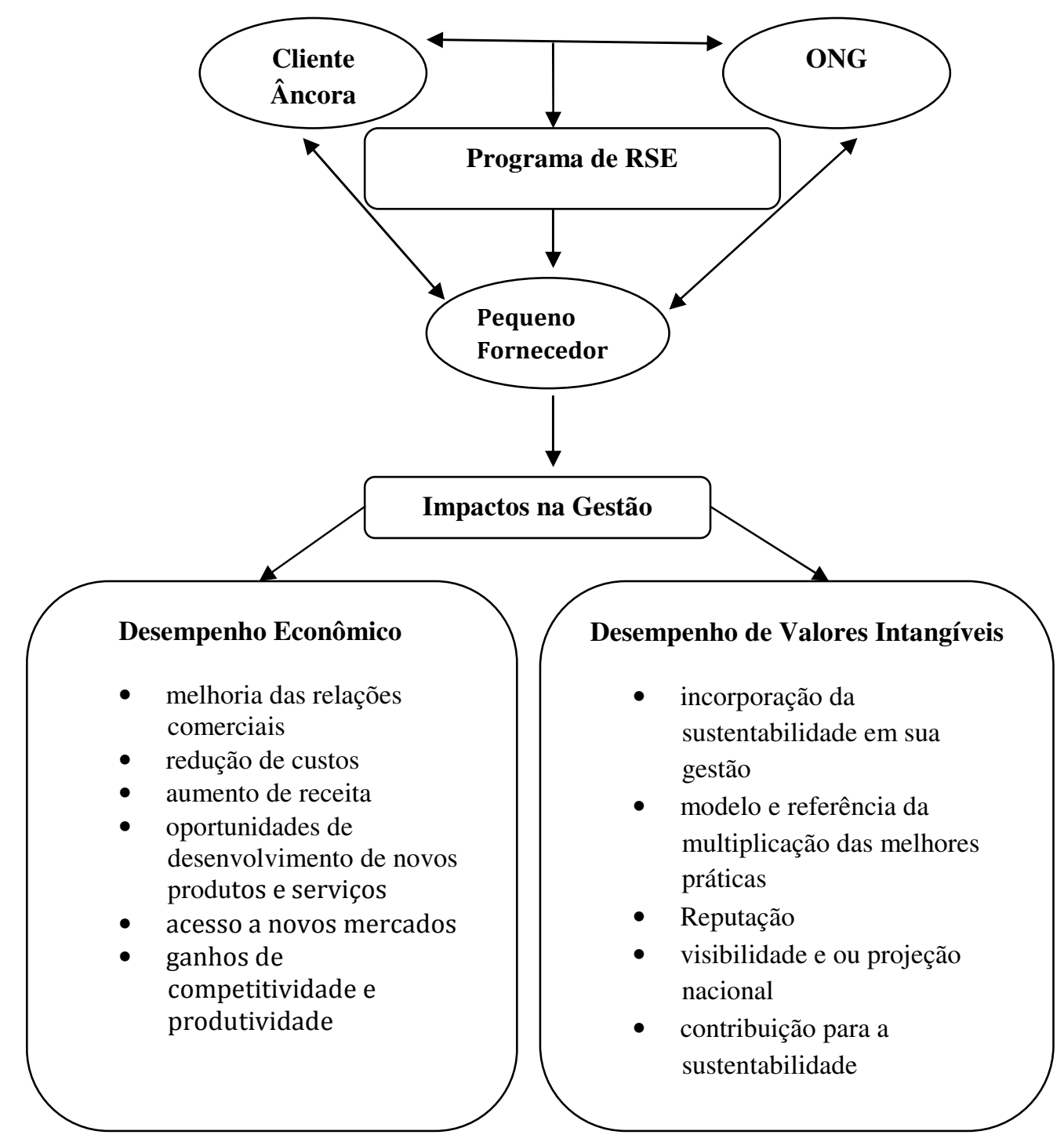

Figura 1 - Modelo Conceitual

Fonte: Elaborado pelos autores

O pequeno fornecedor ocupa o lugar central da figura e, portanto, o ponto de tensão de todo o processo que está sendo estudado, pois a influência se dá na direção descendente, partindo das empresas - âncora e das Ongs a orientação de adoção de ações sociais. Os resultados de tal procedimento são mostrados logo abaixo em dois vetores: tangíveis, ou desempenho econômico e, intangíveis ou valores de responsabilidade social. 


\section{METODOLOGIA}

\subsection{Desenho da Pesquisa}

O foco do estudo residiu em entender uma situação específica, ou seja, o processo de influência da empresa-âncora sobre PME fornecedoras quando relacionado à assimilação de práticas de gestão socialmente responsáveis. Durante a pesquisa tornou-se absolutamente relevante considerar que a relação entre as duas empresas não era apenas no âmbito clientefornecedor, mas considerar o grau de influência e poder que a grande empresa-âncora tinha na relação. Atentar para o fato de que a empresa- cliente exercia um grande poder de influência sobre a fornecedora, sendo essa empresa de grande porte e reconhecida como uma das maiores de sua indústria. Daí a denominação empresa-âncora. De acordo com Porter (1980), pode-se supor que a âncora detinha forte poder de barganha sobre os fornecedores.

A ideia inicial do Programa Tear residiu em considerar o poder da âncora para influenciar a PME sob o argumento de que a RSE impacta positivamente no desempenho da empresa, uma vez que incrementa condições de competitividade e sustentabilidade. As premissas assumidas no início da análise foram:

Premissa 1 - A gestão orientada pelos interesses dos stakeholders impacta na performance das empresas (FASSIN, 2009; FREEMAN, 1984, 1994; GREENLEY; FOXALL, 1997; MITCHELL; AGLE; WOOD, 1997);

Premissa 2 - Existe uma relação positiva entre gestão orientada por interesses de stakeholders, adoção de práticas de gestão socialmente responsáveis e desempenho competitivo nas organizações (GRIFIN; MAHON, 1997; HARRISON; FREEMAN, 1999; MCGUIRE; SUNDGREEN; SCHNEEWEIS, 1988; PUNCHEVA, 2008; RUF et al, 2001; SPENCE; COLES; HARRIS, 2001; WADDOCK; GRAVES, 1997; WOOD, 1991);

Premissa 3 - A RSE não está restrita a empresas grandes, que detêm recursos suficientes para influenciar o ambiente e impor regras para a realização dos negócios, de acordo com princípios da RSE. As PME também podem assimilar a RSE e usufruir de impactos positivos em termos de competitividade e sustentabilidade (AVRAM; KÜHNE, 2008; FULLER; TIAN, 2006; JENKINS, 2009; LONGO; MURA; BONOLI, 2005; MANKELOW, 2008; ROBERTS; LAWSON; NICHOLLS, 2006; SPENCE, 2007; WILLIAMSON; LYNCH-WOOD; RAMSAY, 2006);

Premissa 4 - Medir o grau de aderência das empresas aos protocolos pré estabelecidos pelos Indicadores de RSE do Instituto Ethos. Devido ao seu papel de 
"ferramenta" no auxilio às empresas em seu planejamento de ações e monitoramento da RSE, julgou-se apropriado sua adoção como base operacional para acompanhar o desempenho das PME participantes do estudo neste quesito. Os Indicadores são estruturados na forma de questionários, dispostos em quadro contíguos e representam uma escala evolutiva de parâmetros que as organizações podem utilizar como referência no desenvolvimento de sua gestão socialmente responsável. Os temas analisados são: Valores, Transparência e Governança, Público Interno, Meio Ambiente, Fornecedores, Consumidores e Clientes, Comunidade, e Governo e Sociedade. Por sua vez, o papel das âncoras foi analisado com base na sua capacidade de viabilizar o conhecimento e servir como facilitador para que as PME adotassem as práticas, segundo as orientações do Instituto Ethos, por meio da Metodologia Tear de trabalho em cadeia de valor (INSTITUTO ETHOS DE EMPRESAS E RESPONSABILIDADE SOCIAL, 2008).

Considerando o interesse por entender mais profundamente como se dá a estimada influência, a opção pelo estudo múltiplo de casos com caráter qualitativo pareceu a mais adequada. Godoy (2006) apoia-se em Stake (1988, 2000) e em Merriam (1988; 1998) para explicar que esse é o caso de analisar o fenômeno por meio de uma descrição holística e intensa, seja ele, indivíduo, programa, empresa ou um grupo de pessoas que compartilham o mesmo ambiente de trabalho.

Merriam (1988) acentua que a escolha pelo estudo de caso denota ser o interesse do pesquisador mais voltado à compreensão dos processos sociais que ocorrem em determinado contexto, do que relações estabelecidas entre variáveis. É a estratégia de pesquisa adequada para compreender uma situação em profundidade, enfatizando seu significado para os vários envolvidos. Constitui uma estratégia de pesquisa interessante quando se deseja entender um fenômeno social complexo, pois pressupõe um maior nível de detalhamento das relações entre os indivíduos e as organizações, bem como dos intercâmbios que se processam com o meio ambiente nos quais estão inseridos (YIN, 2005).

Yin (2005) afirma que o estudo de caso é uma estratégia de pesquisa interessante quando as perguntas de pesquisa incluem como, porque e "quando o pesquisador tem pouco controle sobre os eventos" (YIN, 2005, p. 19). O método de estudos de casos múltiplos permite a observação de evidências em diferentes contextos, pela replicação do fenômeno, sem necessariamente se considerar a lógica de amostragem. 


\subsection{Unidades de Análise}

As âncoras foram escolhidas entre os membros do Instituto Ethos, tendo como base empresas com experiências avançadas em gestão socialmente responsável, atentando para escolher uma âncora por setor. Durante o Programa Tear cada âncora possuiu em torno de 15 PME fornecedoras. Considerou-se como PME empresas com faturamento até US\$ 5 milhões por ano e escolheu-se organizações consideradas estratégicas para a empresa âncora, detentoras de tecnologia singular, potencial exportadora ou servir como multiplicadora das ações (INSTITUTO ETHOS DE EMPRESAS E RESPONSABILIDADE SOCIAL ,2008). A seleção intencional de duas empresas fornecedoras de variados tipos de negócios em âncoras diferentes justifica-se no fato de obter uma melhor exploração da disseminação da metodologia do Programa Tear, assim como da comparação dos impactos gerados pelos resultados de ações socialmente responsáveis. O quadro 1 apresenta a estrutura dos três casos compostos pelas nove empresas. Dentre todas as âncoras participantes do programa, escolheuse por conveniência e acessibilidade, empresas dos setores de mineração, construção civil e siderurgia. As PME escolhidas foram Leili Refrigeração, prestadora de serviços de refrigeração e eletrônica; Bugue Reciclagem, recicladora de sucata industrial; Andaimes Metax, prestadora de serviços e soluções em acesso e transporte vertical; Roca Engenharia, prestadora de serviços em fundações e geotecnia; Degraus Engenharia, empresa no setor de construção civil e Unidata Automação, empresa do setor de informática e automação.

A partir de três conjuntos de coleta e análise chamados de Caso 1 (ArcelorMittal, Bugue e Leili), Caso 2 (Camargo Corrêa, Metax e Roca) e Caso 3 (Vale, Degraus e Unidata) desenvolveu-se a pesquisa, considerando-se a relação entre cliente-fornecedor, mas, também o grande poder de influência da âncora sobre seus fornecedores.

\begin{tabular}{|c|c|c|c|}
\hline $\begin{array}{l}\text { Estudo de } \\
\text { Caso }\end{array}$ & $\begin{array}{ll}\text { Setor } & \text { de } \\
\text { Indústria } & \end{array}$ & $\begin{array}{l}\text { Empresa } \\
\text { Âncora }\end{array}$ & PME Fornecedoras \\
\hline \multirow[t]{2}{*}{ Caso 1} & \multirow[t]{2}{*}{ Mineração } & \multirow[t]{2}{*}{ ArcelorMittal } & Leili Refrigeração \\
\hline & & & Bugue Reciclagem \\
\hline \multirow[t]{2}{*}{ Caso 2} & \multirow[t]{2}{*}{ Construção Civil } & \multirow[t]{2}{*}{ Camargo Corrêa } & Andaimes Metax \\
\hline & & & Roca Engenharia \\
\hline \multirow[t]{2}{*}{ Caso 3} & \multirow[t]{2}{*}{ Siderurgia } & \multirow[t]{2}{*}{ Vale } & Degraus Engenharia \\
\hline & & & Unidata Automação \\
\hline
\end{tabular}

Quadro 1: Relação da estrutura dos casos

Fonte: Elaborado pelos autores

REAd - Edição 68, Volume 17, № 1, jan/abr 2011 - p. 204-236 


\subsection{Coleta de Dados}

A fonte primária de dados foi baseada em entrevistas com atores-chaves, apresentadas no Quadro 1. Estas foram registradas em gravador digital manual, padrão voice editing e, posteriormente transcritas para um modelo virtual, para tratamento específico. As entrevistas foram elaboradas de modo a permitir que as perguntas pré-estabelecidas fossem modificadas conforme se atingiam os objetivos ou não da pesquisa. O pré-estabelecimento das perguntas serviu de guia para o avanço e conseqüentemente o sucesso do resultado pretendido.

Cabe explicar como foram selecionados os 19 entrevistados. Nas PME, inicialmente, deu-se atenção a indivíduos que haviam participado diretamente do desenvolvimento e implantação do Tear, como responsáveis pelo Programa, assim como nas empresas-âncoras e no Instituto Ethos. Adicionalmente, com o andamento das investigações, houve o cuidado de entrevistar também pessoas que não haviam sido responsáveis diretamente pela implantação do Tear, mas que se envolveram em ações implantadas ao longo do trabalho de disseminação e assimilação da Metodologia. Apenas em uma das PME não foi possível realizar as duas entrevistas.

Desta feita, os relatos coletados nas PME são oriundos tanto de implantadores e como de participantes, o que aumenta a riqueza da coleta e a robustez das conclusões. Tal procedimento é aconselhado por Godoy (2006), para quem a definição dos entrevistados durante o processo de estudo - sem a preocupação da representatividade estatística -, atribui ao pesquisador a flexibilidade de voltar ao campo e ampliar o número ou aprofundar a conversação com os participantes. Para a autora, a evolução da compreensão analítica dá consistência ao tema de investigação, e em última análise, constituindo o critério que orienta o trabalho de campo.

No caso do Instituto Ethos foram entrevistadas as Indutoras, pessoas-chaves para a implantação do Programa nas PME, segundo a nomenclatura utilizada na Metodologia Tear de trabalho em cadeia de valor (INSTITUTO ETHOS DE EMPRESAS E RESPONSABILIDADE SOCIAL, 2008), além da Coordenadora do Programa Tear e o Presidente do Instituto.

Nas âncoras, os três entrevistados foram profissionais responsáveis pelo desenvolvimento de ações de Responsabilidade Social em suas corporações, também responsáveis pela promoção e integração do Programa Tear na cadeia de PME fornecedoras.

REAd - Edição 68, Volume 17, № 1, jan/abr 2011 - p. 204-236 
O Quadro 2 apresenta a relação de empresas e entrevistados para os 3 conjuntos deste estudo.

\begin{tabular}{|c|l|}
\hline \multicolumn{1}{|c|}{ EMPRESA } & ENTREVISTADO (cargo ou posição na hierarquia) \\
\hline ArcelorMittal & $\begin{array}{l}\text { Analista de Recursos Humanos, responsável pela promoção e } \\
\text { integração do programa na cadeia de PME fornecedoras }\end{array}$ \\
\hline Bugue Reciclagem & $\begin{array}{l}\text { Gerente Administrativo, responsável pela implantação do programa } \\
\text { na empresa }\end{array}$ \\
\hline Leili Refrigeração & $\begin{array}{l}\text { Coordenadora da Qualidade, responsável pela implantação do } \\
\text { programa na empresa } \\
\text { Auxiliar Administrativo, participante do programa }\end{array}$ \\
\hline Camargo Corrêa & $\begin{array}{l}\text { Analista de Desenvolvimento Organizacional, responsável pela } \\
\text { promoção e integração do programa na cadeia de PME fornecedoras }\end{array}$ \\
\hline Metax & $\begin{array}{l}\text { Coordenadora do Sistema de Gestão da Qualidade, responsável } \\
\text { pela implantação do programa na empresa } \\
\text { Gerente Comercial, participante do programa }\end{array}$ \\
\hline Roca & $\begin{array}{l}\text { Sócio-diretor Comercial, responsável pela implantação do programa } \\
\text { na empresa prama } \\
\text { Engenheiro Civil, participante do programa }\end{array}$ \\
\hline Vale & $\begin{array}{l}\text { Supervisor de Recursos Humanos, responsável pela promoção e } \\
\text { integração do programa na cadeia de PME fornecedoras }\end{array}$ \\
\hline Instituto Ethos & $\begin{array}{l}\text { Coordenador da Qualidade, responsável pela implantação do } \\
\text { programa na empresa } \\
\text { Técnica em Segurança do Trabalho, participante do programa }\end{array}$ \\
\hline Unidata Automação & $\begin{array}{l}\text { Gerente de Operações, responsável pela implantação do programa na } \\
\text { empresa } \\
\text { Encarregada de Operações, participante do programa }\end{array}$ \\
\hline $\begin{array}{l}\text { Presidente do Instituto } \\
\text { Indutora A (AcelorMittal e Vale) } \\
\text { Indutora B (Camargo Corrêa) }\end{array}$ \\
\hline
\end{tabular}

Quadro 2: Relação de entrevistados nas empresas-âncoras, PME e Instituto Ethos de Empresas e Responsabilidade Social

Fonte: Elaborado pelos autores

Além das entrevistas, houve ampla coleta de documentos, incluindo: Metodologia Tear de trabalho em cadeia de valor; Relatórios de gestão das empresas âncoras e das PME; e a denominada Linha de Base: orientação desenvolvida pelo Instituto Ethos para garantir a consolidação do Programa Tear. Nesse documento, de acesso restrito e sob guarda e responsabilidade de cada empresa participante, são descritos os desempenhos econômicos, diagnósticos, níveis de utilização de RSE pelas PME validados pelos Indicadores Ethos de RSE, além de outros dados de desempenho e avaliação do programa. (INSTITUTO ETHOS DE EMPRESAS E RESPONSABILIDADE SOCIAL, 2008).

Ressalta-se que os relatórios Linha de Base constituem peça chave para que cada PME priorize um conjunto de indicadores, defina ações para implantá-los e as acompanhe. 
Adicionalmente houve a participação em vários encontros periódicos de trabalho, em discussões plenárias e eventos promovidos pelo Instituto Ethos e pelas empresas âncoras.

Nestes eventos foi possível participar dos planos de ações das PME estudadas e observar como foram identificados indicadores não atendidos pelas práticas, processos e procedimentos da empresa e, como se estabeleceram metas de curto, médio e longo prazo a fim de priorizar, ordenar e implementar planos de ação, e seu conseqüente monitoramento.

\subsection{Análise dos Dados}

A análise dos dados foi elaborada em quatro fases, seguindo a proposta metodológica de Maguire, Hardy e Lawrence (2004). Na primeira fase, elaborou-se uma narrativa geral que permitiu vislumbrar a relação entre as organizações envolvidas distribuídas nos 3 conjuntos de casos nos procedimentos, eventos e fatos relevantes ao longo do processo de assimilação de práticas de RSE nas PME.

Nos contatos preliminares realizados em entrevistas informais, a participação da empresa no Programa Tear foi reportada sempre como positiva e frutífera, principalmente pelos entrevistados que participaram diretamente dos encontros e plenárias. Ficou claro que para fugir do discurso oficial padrão, seria necessária investigação bem mais profunda. Outros pontos importantes tinham que ser levantados, por exemplo: as dificuldades encontradas pelas PME para adotarem práticas de RSE e os resultados efetivamente alcançados pelas PME ao se envolverem com o Tear.

Na segunda fase de análise, recorreram-se a novas coletas ou validação dos dados já levantados em entrevistas anteriores e documentos. Procedeu-se a uma avaliação dos indicadores escolhidos por cada PME e como efetivamente foram traduzidos em ações ou práticas de gestão. Destacaram-se nesta fase os resultados em termos de antes do Tear e depois do Tear.

$\mathrm{Na}$ terceira fase foram identificados os principais pontos em comum que emergiram das análises dos casos e que se referiam a como as PME lidaram com a participação no Tear, a assimilação de práticas de RSE e a natureza da relação com a âncora e com o Instituto Ethos. Nesta fase elegeram-se categorias para explicar em grandes linhas as evidências de resultados na gestão das PME após a participação no Tear. Por fim, na quarta fase de análise tratou-se diretamente das perguntas de pesquisa em relação às categorias que emergiram das outras três fases.

REAd - Edição 68, Volume 17, № 1, jan/abr 2011 - p. 204-236 
A Metodologia do Programa Tear, a partir de encontros periódicos, orientou que cada pequena empresa deveria preencher os Indicadores Ethos e efetuar uma análise qualitativa das práticas de RSE (INSTITUTO ETHOS DE EMPRESAS E RESPONSABILIDADE SOCIAL, 2008). Os questionários preenchidos dos Indicadores são processados e transformados em nível de utilização ou aproveitamento de RSE, o qual se atribui notas de 0 (zero) a 10 (dez), e apresentados em um Relatório de Diagnóstico, software de acesso exclusivo para as empresas respondentes no endereço eletrônico do Instituto Ethos ( www.ethos.org.br). As empresas podem então compará-los por meio de tabelas e gráficos, com um grupo de benchmarking composto por dez empresas com os melhores níveis de utilização da RSE e com a média do grupo que responderam ao questionário no mesmo período.

Nestes encontros foi identificado o estágio de desenvolvimento em RSE de cada PME participante e formalizados objetivos para o desenvolvimento de ações em níveis diretivo, estratégico e operacional de acordo com os principais elementos de sistema de gestão da RSE, conforme os temas determinados pelos Indicadores de Responsabilidade Social do Instituto Ethos.

Admitiu-se que cada PME priorizasse temas, elegesse indicadores e estabelecesse um conjunto de ações de maneira a contemplar todos os seus stakeholders, levando-se em conta os fatores críticos do negócio, e parâmetros de legitimidade, comparabilidade e aplicabilidade.

\section{RESULTADOS E DISCUSSÃO}

A base adotada para a análise dos resultados foi avaliar as práticas da RSE por sua abrangência e profundidade, segundo os temas dos Indicadores Ethos de Responsabilidade Social Empresarial, conforme mencionado na Metodologia.

Os temas são divididos em um conjunto de indicadores, totalizando quarenta indicadores, formados por questões de profundidade, questões binárias e questões quantitativas. Os indicadores ou questões de profundidade permitem avaliar, por meio de quadros contíguos o nível de estágio (de 1 - um a 4 - quatro) e desempenho da empresa em relação às ações socialmente responsáveis, e evoluem do primeiro até o quarto estágio. As questões binárias ( $\operatorname{sim}$ ou não) qualificam as respostas escolhidas no indicador de profundidade e contribuem na decisão de quais práticas devem ser incorporadas à gestão da empresa. Os indicadores quantitativos realizados a partir do levantamento de dados anuais da empresa são úteis no monitoramento interno da empresa e no planejamento da implantação de

REAd - Edição 68, Volume 17, No 1, jan/abr 2011 - p. 204-236 
ações por meio dos Indicadores Ethos. Os indicadores de profundidade fornecem parâmetros para os passos subseqüentes e atrelados aos outros indicadores resultarão no nível de aproveitamento da RSE qualificado por notas de 0 (zero) a 10 (dez).

O nível de aproveitamento de RSE das PME dos casos estudados, após a adoção do Programa Tear constam no Quadro 3.

\begin{tabular}{|l|l|l|l|}
\hline Tema & $\begin{array}{l}\text { Caso 1 - ArcelorMittal, } \\
\text { Bugue Reciclagem e } \\
\text { Leili Refrigeração }\end{array}$ & $\begin{array}{l}\text { Caso 2 - Camargo Corrêa, } \\
\text { Metax e } \\
\text { Roca Fundações }\end{array}$ & $\begin{array}{l}\text { Caso 3 - Vale, } \\
\text { Degraus e } \\
\text { Unidata }\end{array}$ \\
\hline $\begin{array}{l}\text { Valores, } \\
\text { Transparência e } \\
\text { Governança }\end{array}$ & 2,34 & 3,38 & 6,82 \\
\hline Público Interno & 4,17 & 6,81 & 6,20 \\
\hline Meio Ambiente & 4,30 & 0,89 & 4,65 \\
\hline Fornecedores & 4,75 & 0,44 & 1,90 \\
\hline $\begin{array}{l}\text { Consumidores e } \\
\text { Clientes }\end{array}$ & 0 & 8,18 & 5,00 \\
\hline Comunidade & 2,48 & 0 & 1,17 \\
\hline Governo e Sociedade & 0,88 & 0 & 0 \\
\hline
\end{tabular}

\section{Quadro 3: Resultado dos Níveis de Utilização de RSE pelas PME estudadas.}

Fonte: Elaborado pelos autores

$\mathrm{Na}$ análise comparativa, a partir do nível de aproveitamento das ações socialmente responsáveis, evidenciou-se um padrão em relação ao tema Público Interno que possuía média total superior aos outros itens. A média se deve aos indicadores priorizados e seu desempenho no nível de utilização de RSE, os quais foram: Compromisso com o desenvolvimento profissional, a empregabilidade e o desenvolvimento infantil; Critérios de contratação; Gestão participativa e Acesso à informação; Cuidados com saúde, segurança e Condições de trabalho; Política de remuneração; Política de Benefícios e carreira; Valorização da diversidade e Promoção da eqüidade.

Vale ressaltar que as pequenas empresas do Caso 2 obtiveram um nível de aproveitamento considerado alto em relação às suas prioridades relativas ao tema Consumidores e Clientes, pois priorizaram os indicadores Desenvolvimento de políticas de comunicação comercial; Canais de comunicação com consumidores e clientes; e Estabelecimento de setores internos de suas organizações para dirimir dúvidas, sugestões e reclamações, buscando assim a satisfação dos consumidores e ou clientes.

Observa-se também que no Caso 3 houve um nível de aproveitamento relativamente alto no tema Valores, Transparência e Governança. Fato este devido a priorização dos REAd - Edição 68, Volume 17, No 1, jan/abr 2011 - p. 204-236 
indicadores Compromissos Éticos; Governança Corporativa; Balanço Social e Práticas Antipropina.

Os indicadores econômicos, referentes aos anos em que as pequenas empresas estudadas participaram do Tear, apontaram para um crescimento acima do crescimento da economia brasileira. Para se ter uma ideia, no triênio 2005/2007 o PIB brasileiro ficou em média 4,3\% (INSTITUTO BRASILEIRO DE GEOGRAFIA E ESTATÍSTICA, 2009) e o crescimento do faturamento médio das micro e pequenas empresas paulistas ficou na ordem de 0,54\% (SERVIÇO DE APOIO ÀS MICRO E PEQUENAS EMPRESAS DE SÃO PAULO, 2009). Já o faturamento dos três conjuntos dos estudos de casos ficou em média $13,5 \%, 15,0 \%$ e $60,5 \%$, respectivamente. Os resultados verificados em relação ao desempenho econômico foram de forma positiva. Além do aumento de receita, houve redução de custos operacionais. Para o conjunto de pequenas empresas do Caso 1, as despesas operacionais ficaram em média em 7,5\%. Para o conjunto de pequenas empresas do Caso 2, as despesas operacionais ficaram em $12,0 \%$ e para o Caso 3 em 50,0\%. Observou-se que as pequenas empresas do Caso 3 obtiveram um aumento de suas receitas bem superior aos demais casos. No entanto não há evidências que justifiquem tal desempenho, nem pelas ações socialmente responsáveis, particularmente desenvolvidas por este conjunto, e nem por negócios a partir da relação com a empresa-âncora.

Desta forma em relação às Premissas 1 e 2, ainda que haja evidência de que as pequenas empresas aumentaram o faturamento, não se pode creditar tal fato a nenhuma ação ou evento específico relacionado às ações socialmente responsáveis. Não há menção de que houve mudanças no relacionamento comercial com as âncoras, ainda que ocorressem iniciativas de comunicação e troca de experiências. Os dados coletados não revelam qualquer condição de estabelecer relação direta entre a adoção de práticas de responsabilidade social e o desempenho financeiro corporativo. Neste sentido, os resultados apontam para o que sugere o trabalho de Fombrun e Gardberg (2000); a impossibilidade direta em estabelecer tal correlação.

Coube aos colaboradores internos das pequenas empresas o encargo das ações socialmente e ambientalmente responsáveis (COLLIER; ESTEBAN, 2007; FOX, 2008). Estabeleceu-se um sentimento de comprometimento do público interno (WALKER, 1999), o que contribuiu positivamente para o clima organizacional. Estas ações foram apoiadas pela alta direção da pequena empresa, que se predispôs a incorporar mudanças no comportamento e tornarem-nas válidas. Evidencia-se assim também a relevância das competências gerenciais

REAd - Edição 68, Volume 17, No 1, jan/abr 2011 - p. 204-236 
das pequenas empresas. Porém são as percepções positivas dos colaboradores internos que farão com que ações socialmente responsáveis tragam o resultado esperado, pois são eles que vivenciam no dia a dia a aplicação das ações priorizadas. Demonstra-se que não raro, uma questão de sobrevivência e longevidade pode ser a integração da gestão da empresa com seus funcionários no dia a dia das atividades.

Tais evidências tornaram claro que podem existir várias maneiras de se desvendar o papel e a importância de uma organização com suas partes interessadas, às quais estão relacionados aos atributos dos stakeholders. Esses atributos são desenvolvidos por meio de operações que essas organizações mantêm em sua cadeia de valor. O papel e a importância dos stakeholders podem vir imbuídos por formas ou manifestações de influência e poder. Ou podem estar fundados e amparados em reivindicações na esfera do que é justo, do que se convencionou designar por legítimo. Ou ainda, um atributo pode estar fundado no interesse de um comportamento consuetudinário consistente com os princípios da responsabilidade social.

No que concerne a Premissa 3, entendeu-se que para interpretar os interesses das âncoras é importante considerar as implicações das estratégias e políticas orientadas às novas relações das pequenas empresas com tais stakeholders.

As expectativas do Programa alimentavam uma maior incorporação da sustentabilidade em sua gestão, além de aumento de reputação e visibilidade no meio em que atuam as pequenas empresas participantes.

Há, sobretudo, ênfase nos impactos da relação com os colaboradores, funcionários ou terceirizados. São várias as ações: eventos, aulas, coleta seletiva de lixo, reaproveitamento de papel para impressão, incentivos à realização de cursos e complementação da instrução formal, combate ao uso de álcool de drogas, patrocínio a atividades na comunidade circunvizinha, doações a hospitais, creches e escolas públicas, patrocínio de atividades esportivas e de lazer nas cidades ou bairros próximos a cada pequena empresa.

Em outro plano, observa-se também que os stakeholders externos relevantes podem incrementar a gestão de pequenas empresas por meio de troca de informações e compartilhamento de experiências. Tal fato pode ser construído a partir de RSE em rede, sendo esta uma das maneiras de desenvolver novos modelos de gestão. Iniciativas como estas modificam as relações sociais internas nas organizações, disseminam novos comportamentos e podem gerar ações inovadoras nos processos de produção e gestão.

O papel da empresa-âncora era viabilizar o conhecimento e servir como ente incentivador para que a pequena empresa adotasse as práticas seguindo as orientações do 
Instituto Ethos, que funcionou como facilitador de tais métodos. Ser reconhecido como um fornecedor que incorpora práticas de gestão socialmente e ambientalmente responsáveis trouxe proximidade, reputação e destaque para cada pequena empresa em sua cadeia de valor. A literatura aponta que empresas que possuem um capital reputacional fortalecido, aumentam sua capacidade de negociar contratos mais atraentes com fornecedores, de cobrar preços melhores para seus produtos e reduzir seus custos de capital (FOMBRUN; GARDBERG 2000).

Observamos que a heterogeneidade e assimetria dos relacionamentos entre âncoras e pequenas empresas estão diretamente vinculadas ao porte e contexto onde esses atores sociais atuam o que implicará a sujeição à demanda e às condições estabelecidas pelos stakeholders de maior relevância. Tal influência por parte de grandes corporações traz no seu bojo interesses de negociações que venham constituídas de relações domesticadas e horizontalizadas com seus pequenos fornecedores. Fica evidenciada que estas podem ser subliminarmente uma alternativa para que PME se mantenham no mercado, combatendo o alto nível de mortalidade que atinge tais organizações. As ações socialmente responsáveis e a sustentabilidade são tratadas como uma gestão estratégica, na qual os relacionamentos da empresa com indivíduos e as partes interessadas são gerenciados com vista no fortalecimento de sua cadeia de valor e sua rede de contato.

Estabelece-se aí um paradoxo, pois se por um lado grandes clientes buscam relações sujeitas ao seu controle com uma gama diferente de pequenos fornecedores por meio da RSE, estes por sua vez podem desenvolver em sua rede, no segmento de atuação, certo poder e diminuir a assimetria das relações a que estão sujeitos.

As pequenas empresas buscaram o cumprimento de suas responsabilidades, buscaram também sua eficácia e eficiência, o que refletiu na melhoria nas áreas de processo produtivo e administrativo e na gestão corporativa como um todo, demonstrando capacidade de entregar valor para seus stakeholders e adquirindo assim reputação corporativa (PUNCHEVA, 2008). A gestão das ações socialmente responsáveis está diretamente ligada às interações da empresa e seus stakeholders e da comunicação entre as partes, o que resulta na valoração positiva da reputação corporativa. Desta feita, constatamos na pesquisa que as relações tecidas entre organizações por meio de ações socialmente responsáveis podem ser fonte relevante de criação de valor.

REAd - Edição 68, Volume 17, No 1, jan/abr 2011 - p. 204-236 
Tem-se então que os impactos de ações socialmente responsáveis se evidenciam em duas grandes linhas de benefícios relacionados à geração positiva de valor. A primeira se manifesta no campo do clima organizacional e a segunda no âmbito da reputação empresarial.

Quanto à Premissa 4, pôde-se constatar que os indicadores Ethos foram uma ferramenta adequada para a mensuração que se pretendia. Os resultados apareceram na medida em que avançamos nossas análises e interpretações, e vislumbramos novas relações que sobressaiam em nossa pesquisa. Assim, observou-se que as pequenas empresas priorizaram mais vezes o tema Público Interno que as demais, tendo em média maior frequência de ações em todas as empresas estudadas. O tema Valores, Transparência e Governança aparecem em segundo lugar como prioridade escolhida no campo da elaboração de códigos de conduta e divulgação a colaboradores internos e externos de informações econômicas e financeiras das empresas. A seguir, em número de prioridades, aparece o tema Meio Ambiente com ações relacionadas à redução de custos por meio de programas internos desenvolvidos junto aos seus funcionários. O tema, Fornecedores se desenvolveu em sua maioria no campo da formalização de políticas de compras. E, o tema, Consumidores e Clientes, estava relacionado a políticas de comunicação comercial como elaboração de material de informação aos clientes sobre as características e os riscos dos produtos, e desenvolvimento de canais para dúvidas, sugestão e reclamações. O tema Comunidade foi priorizado apenas por duas PME. O tema, Governo e Sociedade foi priorizado por apenas uma PME, entre os casos estudados, com ações de construção de cidadania. Tal resultado aponta que as ações em sua maioria estiveram voltadas prioritariamente aos reals stakeholders ou stakeholders primários, e que ao assimilarem as abordagens da RSE, fizeram-nas de maneira fragmentada, e na maioria das vezes em itens não diretamente relacionados ao modelo de negócio.

O Quadro 4 resume os resultados organizados pelas 4 Premissas assumidas no estudo e compara-os com os principais autores analisados.

REAd - Edição 68, Volume 17, No 1, jan/abr 2011 - p. 204-236 


\begin{tabular}{|c|c|c|c|}
\hline & Premissa & $\begin{array}{l}\text { Resultado } \\
\text { Relacionado }\end{array}$ & Principais Autores Analisados \\
\hline 1 & $\begin{array}{ll}\text { Gestão orientada aos } \\
\text { stakeholders impacta no } \\
\text { desempenho organizacional }\end{array}$ & $\begin{array}{l}\text { Houve melhoria de } \\
\text { desempenho, mas não } \\
\text { pode ser creditado às } \\
\text { práticas de RSE. }\end{array}$ & $\begin{array}{l}\text { FASSIN,2009;FREEMAN,1994; } \\
\text { GREENLEY;FOXALL, } \\
\text { 1997;MITCHELL;AGLE; WOOD, } \\
\text { 1997 }\end{array}$ \\
\hline 2 & $\begin{array}{l}\text { Relação positiva entre gestão } \\
\text { prientada por interesses de } \\
\text { ttakeholders, adoção de práticas } \\
\text { le gestão socialmente } \\
\text { esponsáveis e desempenho } \\
\text { fompetitivo nas organizações }\end{array}$ & $\begin{array}{l}\text { A análise dos dados não } \\
\text { evidencia relação } \\
\text { positiva por meio de } \\
\text { fato relevante ou } \\
\text { incidente crítico. }\end{array}$ & $\begin{array}{l}\text { PUNCHEVA, 2008; RUF et al, } \\
\text { 2001; SPENCE; COLES; HARRIS, } \\
\text { 2001; WADDOCK; GRAVES, } \\
\text { 1997; WOOD, 1991); }\end{array}$ \\
\hline 3 & $\begin{array}{l}\text { A RSE não está restrita a } \\
\text { empresas grandes. }\end{array}$ & $\begin{array}{l}\text { Constatou-se que as } \\
\text { relações tecidas entre as } \\
\text { PME, âncoras e } \\
\text { Instituto Ethos podem } \\
\text { ser fonte relevante de } \\
\text { criação de valor, } \\
\text { principalmente para } \\
\text { gestão do ambiente } \\
\text { interno. }\end{array}$ & $\begin{array}{lrr}\text { AVRAM; } & \text { KÜHNE, } & 2008 ; \\
\text { FULLER; TIAN, 2006; JENKINS, } & \text { 2005; } \\
2009 ; & \text { BONOLI, r } \\
\text { MANKELOW, 2008; } & \text { SPENCE, } \\
2007 & & \end{array}$ \\
\hline 4 & $\begin{array}{l}\text { Indicadores Ethos } \text { de } \\
\text { Responsabilidade } \\
\text { constituem medida legitima e } \\
\text { relevante para avaliação de } \\
\text { grau de aderência a } \\
\text { responsabilidade } \\
\text { empresarial social }\end{array}$ & $\begin{array}{l}\text { Os indicadores Ethos } \\
\text { foram ferramenta } \\
\text { adequada para a } \\
\text { mensuração pretendida, } \\
\text { uma vez que o estudo } \\
\text { envolveu metodologia } \\
\text { desenvolvida } \\
\text { implantada pelo próprio } \\
\text { Instituto. }\end{array}$ & $\begin{array}{lrr}\text { INSTITUTO } & \text { ETHOS } & \text { DE } \\
\text { EMPRESAS } & & \text { E } \\
\text { RESPONSABILIDADE } & \text { SOCIAL, } \\
2007 & & \end{array}$ \\
\hline
\end{tabular}

Quadro 4 - Comparativo entre as Premissas e Principais Resultados e Autores

Fonte: Elaborado pelos autores

Com base nas Premissas adotadas pode-se, de uma perspectiva ampla, confirmar que uma das possibilidades positivas da implantação das ações socialmente responsáveis aponta na direção do que sugeriram Fombrun e Gardberg (2000) e O'Riordan e Fairbrass (2008) que vinculam tais práticas à atenuação de riscos, a fim de reduzir várias formas de crises corporativas.

Já se observou que há evidências de grandes stakeholders clientes utilizarem ações institucionais de pequenas empresas fornecedoras para exercer pressão no comportamento, nos resultados e para que estes ajam em conformidade com as normas do ambiente em que atuam (PUNCHEVA, 2008). Tais demandas dos stakeholders relevantes determinam de certa forma as escolhas e prioridades na gestão das pequenas empresas. Fica evidente que o desenvolvimento de uma ideologia hegemônica, em que só se estabelece quem responde a determinados requisitos (CULPAN; TRUSSEL, 2005; KING, 2008; MITCHEL; AGLE; REAd - Edição 68, Volume 17, No 1, jan/abr 2011 - p. 204-236 
WOOD, 1997;) das aspirações dos intervenientes de uma empresa, gera valor na medida em que a reputação destas organizações se torna um dos resultados do sucesso da formulação de suas estratégias organizacionais.

Neste sentido as práticas socialmente responsáveis da gestão e suas abordagens (WINDSOR, 2006) podem oferecer às pequenas empresas uma oportunidade de melhorar seu autocontrole institucional (WOOD, 2008). Atenuações de riscos da reputação a partir de ações socialmente responsáveis podem ser desenvolvidas mesmo de maneira não declarada ou não intencional por parte dos gestores da pequena empresa. Neste cenário, o estudo apontou que ações socialmente responsáveis podem funcionar como atenuação dos riscos de sobrevivência que pequenas empresas sofrem no macroambiente em que atuam.

Outra evidência de resultado encontrado em relação à gestão socialmente responsável é que, apesar de ter havido geração de valores intangíveis, não há relatos suficientes para afirmar que as ações socialmente responsáveis impactaram no desempenho em termos econômicos ou competitivos dos negócios, apesar de existirem suposições que tais práticas podem levar à melhoria no desempenho. A RSE mobiliza pessoas, recursos e ações, mas é necessário, ainda mais estudos para avaliar a existência de impactos no desempenho ou nas oportunidades de mercado.

Destarte, o cenário que se vislumbra a partir das relações observadas favorece pensar que os movimentos recentes em prol de ações socialmente responsáveis estão relacionados em estratégias cujas habilidades da gestão poderão promover a longevidade organizacional por meio da integração simultânea com seus stakeholders na esfera econômica, ambiental e social, a fim de criar valor para todos.

\section{CONSIDERAÇÕES FINAIS}

O propósito do estudo foi analisar, por meio de um estudo múltiplo de casos, como grandes empresas influenciam seus fornecedores, as PME em prol da adoção de práticas de gestão socialmente responsáveis e também quais os desafios, barreiras ou acessos para as PME adotarem tais práticas. Ao analisar os diversos entendimentos que se buscam a respeito da RSE e das justificativas usadas para a inclusão deste modelo de gestão nas corporações, pode-se concluir que sua concepção segue duas grandes linhas simultâneas: uma de teor teórico, que busca na pluridade das ideias sua abstração, e outra de caráter prático, que reflete 
no uso instrumental a pretensão de gerir respostas às contradições das relações socioeconômicas.

O estudo teve como foco a PME, com as várias peculiaridades e desafios deste campo. Sem embargo, há evidências que as PME preferem aprender por meio de redes e de seus pares (JENKINS, 2006; MURILO; LOZANO, 2009), o que torna possível seu maior envolvimento com ações social e ambientalmente responsáveis. Não obstante, pode-se observar que as pequenas empresas têm sido influenciadas e afetadas pelos sistemas de valores individuais e organizacionais de sua cadeia de valor e pela rede formada por seus stakeholders (TILLEY, 2000), como pode ser observado na Figura 2.

A Figura 2 procura mostrar que a tendência é as PME possuirem pouco ou nenhum poder de influência sobre as imposições e mudanças do macroambiente (CÊRA; ESCRIVÃO FILHO, 2003). Entretanto os aspectos positivos são que iniciativas como programas de inclusão e disseminação da RSE em rede modificam as relações sociais internas nas organizações, disseminam novos comportamentos e geram valor na forma de reputação positiva para as empresas que fazem parte desta rede.

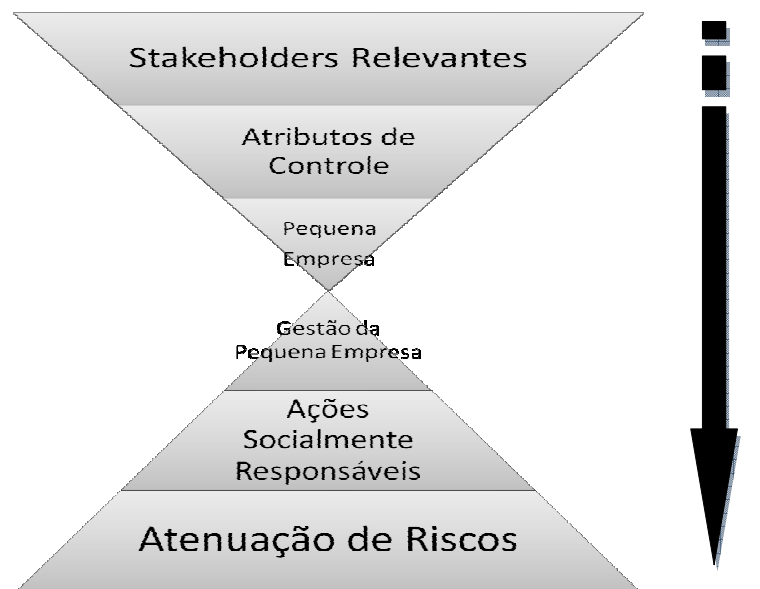

Figura 2: Modelo dos Impactos das Ações Socialmente Responsáveis

Fonte: Elaborado pelos autores

Analogamente, dado que a gestão é a base funcional da empresa (FASSIN, 2008), tem-se que um esquema representativo da maneira como se dão os impactos de ações sociais e ambientais responsáveis por meio das relações entre os stakeholders relevantes e as pequenas empresas que pode ser expresso pelo modelo acima. Desta forma pode-se propor a seguinte interpretação: a partir da premissa de que as pressões que pequenas organizações têm recebido de stakeholders relevantes para implantar uma gestão fundamentada em ações socialmente responsáveis, estas podem implicar a melhoria da gestão e podem desenvolver práticas que REAd - Edição 68, Volume 17, No 1, jan/abr 2011 - p. 204-236 
funcionem como atenuação de riscos, a fim de reduzir várias formas de crises na pequena empresa.

O modelo da Figura 2 é apenas uma representação gráfica das tensões que se desenvolvem entre empresas, mas analisado o seu lado superior pode-se entender que stakeholders externos relevantes têm demonstrado que suas estratégias podem conter políticas para abordar problemas de incentivos às pequenas empresas (MACKENZIE, 2007). Essas estratégias podem ser realizadas por meio de atributos desenvolvidos no macroambiente em que atuam e exercidos como forças impulsionadoras que se dirigem para o cerne da pequena empresa.

A parte inferior da ampulheta inicia-se com a base funcional da pequena empresa que procura gerir adequadamente as relações com seus stakeholders (equilibrando entre o desejado, o necessitado e o possível). Desenvolvem-se então práticas por meio de ações socialmente responsáveis que ajudarão desenvolver um aceitável desempenho (KING, 2008) eficaz e eficiente e servirão na longevidade da pequena empresa. Assim, na base de sustentação da ampulheta estabelece-se uma política com práticas que auxiliarão na atenuação de riscos institucionais e que poderão colaborar para a longevidade da pequena empresa no ambiente em que empreende suas atividades.

A participação no Programa Tear trouxe impactos para as PME na relação com as empresas-âncoras, em termos de comunicação e trocas de experiência, mas não suscitou necessariamente em novos negócios. Os dados coletados apresentaram melhorias (termo que aparece frequentemente nas entrevistas) nas relações com funcionários e com empresas clientes. As ações dirigidas aos funcionários estiveram voltadas ao relacionamento, informação e educação socioambiental dos colaboradores e familiares.

No entanto, as pequenas empresas ao assimilar e desenvolver ações sociais e ambientais responsáveis fizeram-no em itens não diretamente relacionados ao modelo de negócio. As ações socialmente responsáveis das PME orbitaram na esfera da filantropia, no voluntariado e nas ideias de cidadania, refletindo por vezes o pensamento do pequeno empresário.

Entende-se, pelos resultados, que as ações ainda estão no nível da conscientização das pessoas ou em adotar práticas e comportamentos voltados à cidadania, como coleta seletiva de lixo e promoção de atividades filantrópicas e/ou de apoio a comunidades carentes próximas a cada pequena empresa. Os resultados de maior visibilidade da RSE nas pequenas empresas estão relacionados a mudanças no comportamento de indivíduos, seja isoladamente ou na vida

REAd - Edição 68, Volume 17, No 1, jan/abr 2011 - p. 204-236 
organizacional. Outrossim, tanto âncoras quanto pequenas empresas obtiveram ganhos em termos de reputação na rede de relações e na sociedade em geral.

De qualquer modo, as organizações estudadas desenvolvem suas atividades, praticam seus diálogos sociais e exercem seus atributos na deliberada esfera da influência funcional, ou seja, nas relações operacionais da cadeia de valor.

Apesar das evidências da geração de valor por meio da reputação corporativa e do clima organizacional, observou-se que as demandas dos stakeholders não são necessariamente instrumentos de geração de valor para as pequenas organizações, porém requerem das empresas mecanismos de atenuação de riscos institucionais, o que uma gestão socialmente responsável pode desempenhar.

$\mathrm{Na}$ medida em que há evidências de impactos positivos no clima organizacional e na reputação, pode-se tecer a hipótese, para futuras pesquisas, de que a adoção de práticas de RSE leva à melhoria do desempenho das PME. Torna-se necessário, no entanto, atentar para a existência na literatura acadêmica da falta de evidência científica suficiente para relacionar positivamente RSE e desempenho organizacional.

Entende-se, porém, que qualquer controle desenvolvido por mecanismos conceituais, no campo das ciências sociais, fica a mercê daquilo que Berger e Luckmann (1973) descreveram como o "contínuo processo de modificação da realidade subjetiva" (p. 207). Desta forma, uma vez que um dos resultados encontrados foi na área de clima organizacional e nas relações do público interno com sua gestão, pode-se entender que os papéis desempenhados por tais atores, no campo que articula o econômico, social e político, poderiam ser melhor analisados pela ótica do capital social - que vem ao encontro das ideias de Avram e Kühne (2008) e Perrini (2006) -, e não pela abordagem dos stakeholders.

Faz-se necessário relembrar o caráter exploratório do estudo, sendo inadequado medir qualquer hipótese ou universalizar seus resultados. Um resultado positivo parece indicar que se tornou mais evidente o potencial da RSE como orientação para se analisar o campo das relações interorganizacionais.

Desta forma, apesar de carecer de uma unidade teórica consistente, a RSE, reforçada por uma abordagem que considere a influência dos stakeholders, revelou-se boa candidata a suportar outras investigações nesse campo.

REAd - Edição 68, Volume 17, No 1, jan/abr 2011 - p. 204-236 


\section{REFERÊNCIAS}

AVRAM, D.; KÜHNE, S. Implementing responsible business behavior from a strategic management perspective: developing a framework for Austrian SMEs. Journal of Business Ethics, Dordrecht, v. 82, n. 2, p. 463-475, 2008.

BERGER, P. L.; LUCKMANN, T. A construção social da realidade: tratado de sociologia do conhecimento. Petrópolis: Vozes, 1973

BOLTANSKI, L.; CHIAPELLO, E. EI nuevo espíritu del capitalismo. Tradução de Marisa Péres Colina et al. Madrid: Akal, 2002.

CARROL, A. B. Corporate social responsibility. Business \& Society, Chicago, v. 38, n. 3, p. 268-295, 1999.

CÊRA, K.; ESCRIVÃO FILHO, E. Particularidades de gestão da pequena empresa: condicionantes ambientais, organizacionais e comportamentais do dirigente. In: ENCONTRO DE ESTUDOS SOBRE EMPREENDEDORISMO E GESTÃO DE PEQUENAS EMPRESAS, 3., 2003, Brasília. Anais... Brasília: UEM/UEL/UnB, 2003. p. 796-812.

CLARKSON, M. B. E. A stakeholder framework for analyzing and evaluating corporate social performance. Academy of Management Review, Briar Cliff Manor, v. 20, n. 1, p. 92117. 1995.

CLARKSON, M. B. E. Defining, evaluating, and managing corporate social performance: a stakeholder management model. In: POST, J. E. (Ed.). Research in corporate social performance and policy. Greenwich: JAI Press, 1991. p. 331-358.

CLARKSON, M. B. E. The Toronto conference: reflections on stakeholder theory. Business \& Society, Thousand Oaks, v. 33, n. 1, p. 82-132, 1994.

COLLIER, J.; ESTEBAN, R. Corporate social responsibility and employee commitment. Business Ethics: A European Review, Oxford, v. 16, n. 1, p. 19-33, 2007.

CULPAN, R.; TRUSSEL, J. Applying the agency and stakeholder theories to the enron debacle: an ethical perspective. Business \& Society Review, Oxford, v. 110, n. 1, p. 59-76, 2005.

CURADO, I. B. Responsabilidade legal, responsabilidade social: uma questão de autoridade? In: ENCONTRO DA ASSOCIAÇÃO NACIONAL DE PÓS-GRADUAÇÃO E PESQUISA EM ADMINISTRAÇÃO, 27. 2003. Atibaia. Anais... Rio de Janeiro: ANPAD, 2003. 1 CDROM.

REAd - Edição 68, Volume 17, No 1, jan/abr 2011 - p. 204-236 
DONALSON, T.; PRESTON, L. E. The stakeholder theory of corporation: concepts, evidence and implications. Academy of Management Review, Briar Cliff Manor, v. 20, n. 1, p. 65-91, Jan. 1995.

FASSIN, Y. SMEs and the fallacy of formalising CSR. Business Ethics: A European Review, Oxford, v. 17, n. 4, p. 364-378, 2008.

FASSIN, Y. The stakeholder model refined. Journal of Business Ethics, Dordrecht, v. 84, n. 1, p. 113-135, Jan. 2009.

FERREL, O. C.; FRAEDRICH, J.; FERREL, L. Ética empresarial: dilema, tomada de decisões e casos. Tradução de Ruy Jungmann. Rio de Janeiro: Reichmann \& Affonso, 2001.

FLICK, U. Uma introdução à pesquisa qualitativa. 2. ed. Porto Alegre: Bookman, 2004.

FOMBRUN, C. J.; GARDBERG, N. A. Opportunity platforms and safety nets: corporate citizenship and reputational risk. Business \& Society Review, Oxford, v. 105, n. 1, p.85-107, 2000 .

FOX, A. Get in the business of being green. HR Magazine, Alexandria, v. 53, n. 6, p. 44-50, 2008 .

FREEMAN, R. E. Business ethics at the millenium. Business Ethics Quarterly, Bowling Green, v. 10, n. 1, p. 169-180, Jan. 2000.

FREEMAN, R. E. Strategic management: a stakeholder approach. Boston: Pitman, 1984.

FREEMAN, R. E. Teorias do público interessado. In: COOPER, C. L.; ARGYRIS, C. (Orgs.). Dicionário enciclopédico de administração. Tradução de A. Z. Sanvicente. São Paulo: Atlas, 2003. p. 1335-1341.

FREEMAN, R. E. The politics of stakeholder theory: some future directions. Business Ethics Quarterly, Bowling Green, v. 4, n. 4, p. 409-421, 1994.

FREEMAN, R. E.; WICKS, A. C.; PARMAR, B. Stakeholders theory and "the corporate objective revisited". Organization Science, Hanover, v. 15, n. 3, p. 364-369, May/Jun. 2004.

FRIEDMAN, M. The social responsibility of business to increase its profits. New York Times Magazine, New York, Sept. 13, 1970. p. 32-33.

REAd - Edição 68, Volume 17, No 1, jan/abr 2011 - p. 204-236 
FULLER, T.; TIAN Y. Social and symbolic capital and responsible entrepreneurship: an empirical investigation of SME narratives. Journal of Business Ethics, Dordrecht, v. 67, n. 3, p. 287-304, 2006.

GARRIGA, E.; MELÉ, D. Corporate social responsibility theories: mapping the territory. Journal of Business Ethics, Dordrecht, v. 53, n. 1/2, p. 51-71, 2004.

GODOY, A. S. Estudo de caso qualitativo. In: GODOI, C. K.; BANDEIRA-DE-MELO, R.; SILVA, A. B. Pesquisa qualitativa em estudos organizacionais: paradigmas, estratégias e métodos. São Paulo: Saraiva, 2006. cap. 4

GOMES, A.; MORETTI, S. L. A. A responsabilidade e o social: uma discussão sobre o papel das empresas. São Paulo: Saraiva, 2007.

GREENLEY, G.; FOXALL, G. Multiple stakeholder orientation in UK companies and the implications for company performance. Journal of Management Studies, Oxford, v. 34, n. 2, p. 259-284, Mar. 1997.

GRIFFIN, J. J.; MAHON, J. F. The corporate social performance and corporate financial performance debate. Business \& Society, Chicago, v. 36, n. 1, p. 5-31, Mar. 1997.

HARRISON, J. S.; FREEMAN, R. E. Stakeholders, social responsibility, and performance: empirical evidence and theoretical perspectives. Academy of Management Journal, Briar Cliff Manor, v. 42, n. 5, p. 479-485, 1999.

INSTITUTO BRASILEIRO DE GEOGRAFIA E ESTATÍSTICA. Diretoria de Pesquisas. Coordenação de contas nacionais, referência 2002-2007. Disponível em: $<$ http://www.ibge.gov.br/brasil_em_sintese/tabelas/contas_nacionais_tabela01.htm>. Acesso em: 04 maio 2009.

INSTITUTO ETHOS DE EMPRESAS E RESPONSABILIDADE SOCIAL. Indicadores Ethos de responsabilidade social empresarial. São Paulo, 2007.

INSTITUTO ETHOS DE EMPRESAS E RESPONSABILIDADE SOCIAL. Metodologia Tear de trabalho em cadeia de valor. Disponível em: <http://www.ethos.org.br/_Ethos/documents/MetodologiaTear.pdf>. Acesso em: 20 jul. 2008 .

JENKINS, H. A 'business opportunity' model of corporate social responsibility for smalland medium-sized enterprises. Business Ethics: A European Review, Oxford, v. 18, n. 1, p. 21-36, 2009. 
JENKINS, H. Missing the forest for the trees: a critique of the social responsibility concept and discourse. Business \& Society, Chicago, v. 35, n. 1, p. 7-41, 2006.

JENSEN, M. C. Value maximization, stakeholder theory, and the corporate objective function. Business Ethics Quarterly, Bowling Green, v. 12, n. 2, p. 235 -256, 2002.

KING, B. A social movement perspective of stakeholder collective action and influence. Business \& Society, Chicago, v. 47, n. 1, p. 21-49, 2008.

KREITLON, M. P. A ética nas relações entre empresas e sociedade: fundamentos teóricos da responsabilidade social empresarial. In: ENCONTRO DA ASSOCIAÇÃO NACIONAL DE PÓS-GRADUAÇÃO E PESQUISA EM ADMINISTRAÇÃO, 28., 2004, Curitiba. Anais... Rio de Janeiro: ANPAD, 2004. 1 CD-ROM.

LIPOVESTKY, G. Metamorfoses da cultura liberal: ética, mídia e empresa. Tradução de Juremir Machado da Silva. Porto Alegre: Sulina, 2004.

LOGSDON, J. M.; YUTHAS, K. Corporate social performance, stakeholder orientation, and organizational moral development. Journal of Business Ethics, Dordrecht, v. 16, n. 12/13, p. 1213-1226, Sept. 1997.

LONGO, M.; MURA, M.; BONOLI A. Corporate social responsibility and corporate performance: the case of Italian SMEs. Corporate Governance: The International Journal of Effective Board Performance, London, v. 5, n. 4, p. 28-42, 2005.

.MACKE, J.; CARRION, R. M. Programas sociais corporativos: a importância da abordagem transdisciplinar. In: ENCONTRO DA ASSOCIAÇÃO NACIONAL DE PÓS-GRADUAÇÃO E PESQUISA EM ADMINISTRAÇÃO, 30., 2006, Salvador. Anais... Rio de Janeiro: ANPAD, 2006. 1 CD-ROM.

MACKENZIE, C. Boards, incentives and corporate social responsibility: the case for a change of emphasis. Corporate Governance: An International Review, Oxford, v. 15, n. 5, p. 935-943, 2007.

MAGUIRE, S.; HARDY, C.; LAWRENCE, T. B. Institutional entrepreneurship in emerging fields: HIV/AIDS treatment advocacy in Canada. Academy of Management Journal, Briar Cliff Manor, v. 47, n. 5, p. 657-679, 2004.

MANKELOW, G. Social responsibility paradox of small business human resource management practices. International Journal of Human Resource Management, Abingdon, v. 19, n. 12, p. 2171-2181, 2008. 
MARGOLIS, J. D.; WALSH, J. P. Misery loves companies: rethinking social initiatives by business. Administrative Science Quarterly, Ithaca, v. 48, n. 2, p. 268-305, June 2003.

MCGUIRE, J. B.; SUNDGREEN, A.; SCHNEEWEIS, T. Corporate social responsibility and firm financial performance. Academy of Management Journal, Briar Cliff Manor, v. 31, n. 4, p. 854-872, 1988.

MERRIAM, S. B. Case study research in education: a qualitative approach. San Francisco: Jossey-Bass, 1988.

MILES, M. B.; HUBERMAN, A. M. Qualitative data analysis: an expanded sourcebook. $2^{\text {nd }}$ ed. Thousand Oaks: Sage, 1994.

MITCHELL, R.; AGLE, B.; WOOD, D. Toward a theory of stakeholder identification and salience: defining the principle of who and what really counts. Academy of Management Review, Briar Cliff Manor, v. 22, n. 4, p. 853-886, 1997.

MORETTI, S. L. A. A trama e a urdidura: a responsabilidade social das empresas. 2005. Tese (Doutorado) - Programa de Pós-Graduação em Ciências Sociais, Pontifícia Universidade Católica de São Paulo, São Paulo, 2005.

MORETTI, S. L. A.; CAMPANARIO, M. A. A produção intelectual brasileira em Responsabilidade Social Empresarial - RSE sob a ótica da bibliometria. Revista de Administração Contemporânea, Rio de Janeiro, v. 13, ed. especial, p. 68-86, 2009.

MOYSÉS FILHO, J. E., Impactos da implantação de ações socialmente responsáveis em pequenos fornecedores: O Programa Tear. 2009. Dissertação (Mestrado) -Programa de PósGraduação em Administração, Universidade Nove de Julho, São Paulo, 2009.

MOYSÉS FILHO, J. E. e RODRIGUES, A.L. - Responsabilidade Social em Pequenas e Médias Empresas: Uma Análise a Luz da Teoria dos Stakeholders. In: ENCONTRO DA ASSOCIAÇÃO NACIONAL DE PÓS-GRADUAÇÃO E PESQUISA EM ADMINISTRAÇÃO - 33., 2009, São Paulo. Anais... Rio de Janeiro: ANPAD, 2009. 1 CDROM.

MURILO, D.; LOZANO, J. M. Pushing forward SME CRS through a network: an account from the Catalan model. Business Ethics: A European Review, Oxford, v. 18, n. 1, p. 7-20, 2009.

O'RIORDAN, L.; FAIRBRASS, J. Corporate Social Responsibility (CSR): models and theories in stakeholder dialogue. Journal of Business Ethics, Dordrecht, v. 83, n. 4, p. 745$758,2008$.

REAd - Edição 68, Volume 17, No 1, jan/abr 2011 - p. 204-236 
PASSADOR, C. S.; CANOPF, L.; PASSADOR, J. L. Apontamentos sobre a responsabilidade social no ENANPAD: a construção de um conceito? In: ENCONTRO DA ASSOCIAÇÃO NACIONAL DE PÓS-GRADUAÇÃO E PESQUISA EM ADMINISTRAÇÃO, 29., 2005, Brasília. Anais... Rio de Janeiro: ANPAD, 2005. 1 CD-ROM.

PEREIRA, W. A.; CAMPOS, L. A. N. Investigação sobre as semelhanças entre os modelos conceituais da responsabilidade social corporativa. In: ENCONTRO DA ASSOCIAÇÃO NACIONAL DE PÓS-GRADUAÇÃO E PESQUISA EM ADMINISTRAÇÃO, 30., 2006, Salvador. Anais... Rio de Janeiro: ANPAD, 2006. 1 CD-ROM.

PERRINI, F. SMEs and CRS theory: evidence and implications an Italian perspective. Journal of Business Ethics, Dordrecht, v. 67, n. 3, p. 305-316, 2006.

PORTER, M. E. Estratégia competitiva. São Paulo: Campus, 1980.

PUNCHEVA, P. The role of corporate reputation in the stakeholder decision-making process. Business \& Society, Chicago, v. 47, n. 3, p. 272-290, 2008.

ROBERTS, S.; LAWSON, R.; NICHOLLS, J. Generating regional-scale improvements in SME corporate responsibility performance: lessons from responsibility northwest. Journal of Business Ethics, Dordrecht, v. 67, n. 3, p. 275-286, 2006.

RUF, B. M. et al. An empirical investigation of the relationship between change in corporate social performance and financial performance: a stakeholder theory perspective. Journal of Business Ethics, Dordrecht, v. 32, n. 2, p. 143-156, Jul. 2001.

SCHERER, A. G.; PALAZZO, G.; BAUMANN, D. Global rules and private actors: toward a new role of the transnational corporation in global governance. Business Ethics Quarterly, Charlottesville, v. 16, n. 4, p. 505-532, 2006.

SERVIÇO DE APOIO ÀS MICRO E PEQUENAS EMPRESAS DE SÃO PAULO. Pesquisas econômicas séries históricas indicadores Sebrae-SP de conjuntura micro e pequenas empresas do Estado de São Paulo. Disponível em: $<$ http://www.sebraesp.com.br/sites/default/files/series_indicadores_06_09.pdf>. Acesso em: 08 jun. 2009.

SPENCE, L. CSR and small business in a European policy context: the five "C"s of CSR and small business research agenda 2007. Business \& Society Review, Oxford, v. 112, n. 4, p. 533-552, 2007. 
SPENCE, L.; COLES, A. M.; HARRIS, L. The forgotten stakeholder? ethics and social responsibility in relation to competitors. Business \& Society Review, Oxford, v. 106, n. 4, p. 331-353, 2001.

STAKE, R. E. Case studies. In: DENZIN, N. K.; LINCOLN, Y. S. (Eds.). Handbook of qualitative research. $2^{\text {nd }}$ ed. Thousand Oaks: Sage, 2000. p. 435-454.

STAKE, R. E. Case study methods in educational research: seeking sweet water. In: JAEGER, R. M. (Ed.). Complementary methods for research in education. Washington, D.C.: American Educational Research Association, 1988. p. 253-265.

THOMPSON, J. K.; SMITH, H. L. Social responsibility and small business: suggestions for research. Journal of Small Business Management, Oxford, v. 29, n. 1, p. 30-44, 1991.

TILLEY, F. Small firm environmental ethics: how deep do they go? Business Ethics: A European Review, Oxford, v. 9, n. 1, p. 31-41, 2000.

UHLANER, L. M.; GOOR-BALK, H. J. M.; MASUREL, E. Family business and corporate social responsibility in a sample of Dutch Firms. Journal of Small Business and Enterprise Development, v. 11, n. 2, p. 186-194, 2004.

VENTURA, E. C. F. Responsabilidade social das empresas sob a óptica do "novo espírito do capitalismo". In: ENCONTRO DA ASSOCIAÇÃO NACIONAL DE PÓS-GRADUAÇÃO E PESQUISA EM ADMINISTRAÇÃO, 27., 2003. Atibaia. Anais... Rio de Janeiro: ANPAD, 2003. 1 CD-ROM.

WADDOCK, S. A.; GRAVES, S. B. The corporate social performance-financial performance link. Strategic Management Journal, Hoboken, v. 18, n. 4, p. 303-319, 1997.

WALKER, F. D. Corporate character and ethics - a comparative difference? Business \& Society Review, Oxford, v. 1 04, n. 4, p. 439-449, 1999.

WILLIAMSON, D.; LYNCH-WOOD, G.; RAMSAY, J. Drivers of environmental behaviour in manufacturing SMEs and the implications for CSR. Journal of Business Ethics, Dordrecht, v. 67, n. 3, p.317-330, Sept. 2006.

WINDSOR, D. Corporate social responsibility: three key approaches. Journal of Management Studies, Oxford, v. 43, n. 1, p. 93-114, 2006.

WOOD, D. J. Corporate responsibility and stakeholder theory: challenging the neoclassical paradigm. In: AGLE, B. R. et al. Dialogue: toward superior stakeholder theory. Business Ethics Quarterly, Charlottesville, v. 18, n. 2. p. 153-190, 2008.

REAd - Edição 68, Volume 17, No 1, jan/abr 2011 - p. 204-236 
WOOD, D. J. Corporate social performance revisited. Academy of Management Review, Briar Cliff Manor, v. 16, n. 4, p. 691-718, 1991.

YIN, R. K. Estudo de caso: planejamento e métodos. 3. ed. Porto Alegre: Bookman, 2005.

\title{
RESUMO
}

O objetivo deste trabalho foi analisar como grandes empresas influenciam seus fornecedores, nesse caso Pequenas e Médias Empresas (PME), em prol da adoção de práticas de gestão sociais e ambientais responsáveis. Utilizou-se para esse propósito a perspectiva da Responsabilidade Social Empresarial (RSE) que, embora careça de uma unidade teórica consistente, revelou-se mais adequada ao caso. A relevância do estudo se justifica pelo número restrito de trabalhos sobre a RSE em PME e a influência que os stakeholders conceito usado neste caso no sentido de grupos de interesse - exercem sobre essa relação. $\mathrm{O}$ estudo foi realizado dentro do âmbito do Programa Tear - Tecendo Redes Sustentáveis -, que teve como objetivo mobilizar, por meio de grandes empresas (ou âncoras), a adoção de práticas de gestão sociais e ambientais responsáveis por seus fornecedores. Utilizou-se a metodologia do estudo múltiplo de casos com o propósito de analisar tais impactos por meio de três empresas-âncoras e seis PME. Pelos resultados auferidos, pode-se verificar que a influência dos stakeholders acentua a importância e acelera a adoção das práticas de RSE, contudo carece de força para garantir incremento no desempenho, competitividade e oportunidades de mercado. Tal descoberta contraria o objetivo inicial do Programa Tear, conforme foi pregado às PME por seus organizadores.

Palavras-Chave: Responsabilidade Social. Gestão Social e Ambiental em Pequenas e Médias Empresas. Programa Tear. Stakeholders.

\section{SOCIAL AND ENVIROMENTAL MANAGEMENT IN SMALL AND MEDIUM ENTERPRISES: POWER AND INFLUENCE OF STAKEHOLDERS}

\begin{abstract}
The aim of this study was to analyze how large companies influence their suppliers, in this case Small and Medium Enterprises (SMEs), in favor of adopting social and environmental responsibility practices. It was used for this purpose the perspective of Corporate Social Responsibility (CSR) that, although lacks a consistent theoretical unit, was more appropriate to the case. The relevance of the study was justified by the limited number of studies on CSR on SMEs and the influence that stakeholders - in this particular case the concept was used in the sense of interested groups - have on this relationship. The study was conducted within the framework of the Tear Program - Weaving Sustainable Networks - that aimed to mobilize, through large companies (or anchors), the adoption of social and environmental responsibility practices management for its suppliers. The methodology of multiple cases study was used with the purpose of considering such impacts through three anchors companies and six SMEs. According to results, it can be seen that the influence of stakeholders stressed the importance and accelerate the adoption of CSR practices but lacks the strength to ensure an increase in performance, competitiveness and market opportunities. This finding is contrary to the initial objective of the Tear Program, as was nailed to SMEs by its organizers.

Keywords: Social Responsibility. Social and Environmental Management in Small and Medium Enterprises. Tear Program. Stakeholders.
\end{abstract}

REAd - Edição 68, Volume 17, No 1, jan/abr 2011 - p. 204-236 